\title{
Rapidly Growing and Aggressive Cutaneous Squamous Cell Carcinomas in a Patient Treated with Ruxolitinib
}

\author{
Álvaro March-Rodriguez, Beatriz Bellosillo , Alberto Álvarez-Larrán², Carles Besses ${ }^{2}$, \\ Ramon M Pujol, Agustí Toll \\ Departments of Dermatology, ${ }^{1}$ Pathology, and ${ }^{2}$ Hematology, Hospital del Mar, Parc de Salut Mar, Barcelona, Spain
}

Ruxolitinib is a Janus kinase (JAK) 1 and JAK2 inhibitor approved for the treatment of myelofibrosis and for polycythemia patients who are resistant or intolerant to hydroxyurea. We report a 72 year-old man patient with polycythemia vera who developed multiple cutaneous squamous cell carcinomas (cSCCs) with keratoacanthoma-like histological features while on treatment with ruxolitinib. Similar lesions have been reported in an isolated patient who also received ruxolitinib. Our case confirms that ruxolitinib may induce eruptive cSCCs with characteristic clinical and histological features that differentiate them from conventional non-drug induced lesions. Moreover, we performed a mutational panel analysis of the tumors. The lack of specific mutations in these tumors suggests an impairment of immunosurveillance in the origin of the cutaneous lesions. Frequent and thorough dermatological examinations in patients receiving ruxolitinib with a history of photodamage, skin cancer and/or previous hydroxyurea intake is thus recommended. (Ann Dermatol 31(2) $204 \sim 208,2019$ )

\section{-Keywords-}

Carcinoma, squamous cell, Janus kinase 1, Janus kinase 2, Keratoacanthoma, Polycythemia vera

Received March 20, 2017, Revised March 2, 2018, Accepted for publication March 7, 2018

Corresponding author. Álvaro March-Rodriguez, Department of Dermatology, Hospital del Mar, Parc de Salut Mar, Passeig Marítim 25-29 Barcelona 08003, Spain. Tel: 34-932483380, Fax: 34-932483380, E-mail: 61693@parcdesalutmar.cat

ORCID: https://orcid.org/0000-0002-4637-7079

This is an Open Access article distributed under the terms of the Creative Commons Attribution Non-Commercial License (http://creativecommons. org/licenses/by-nc/4.0) which permits unrestricted non-commercial use, distribution, and reproduction in any medium, provided the original work is properly cited.

Copyright (c) The Korean Dermatological Association and The Korean Society for Investigative Dermatology

\section{INTRODUCTION}

Ruxolitinib is a Janus kinase (JAK) 1 and JAK2 inhibitor approved by the Food and Drug Administration and the European Medicines Agency for the treatment of patients with myelofibrosis (either primary or secondary forms) and polycythemia vera (PV) who are resistant or intolerant to hydroxyurea. We report a patient with PV who developed multiple eruptive cutaneous squamous cell carcinomas (cSCCs) while receiving treatment with ruxolitinib.

\section{CASE REPORT}

A 72 year-old man with no significant family medical history and a personal history of hypertension that had been treated for years with amlodipine, fosinopril and hydrochlorothiazide was diagnosed with PV in July 2012. Hydroxyurea and acetylsalicylic acid were prescribed one month later and he was immediately referred to our department to rule out skin cancer in the context of a prospective study of cutaneous manifestations associated with PV and associated treatments. The patient had a Fitzpatrick skin type II and a long sun-exposure history. We detected a facial lentigo maligna, two basal cell carcinomas and one cSCC that had been present for several months. All these lesions were surgically removed with no recurrences. The cSCC was located on the left leg and histologically showed poor differentiation (case 1 in Table 1). In January 2013, five months after hydroxyurea had been prescribed, it had to be withdrawn due to hematological resistance. Ruxolitinib $10 \mathrm{mg}$ twice a day was then initiated. The dose of ruxolitinib was progressively escalated to $15 \mathrm{mg}$ twice a day, dose that was achieved on August 2013. In May 2014, the patient started developing rapidly growing invasive cSCCs. He developed seven primary lesions and 


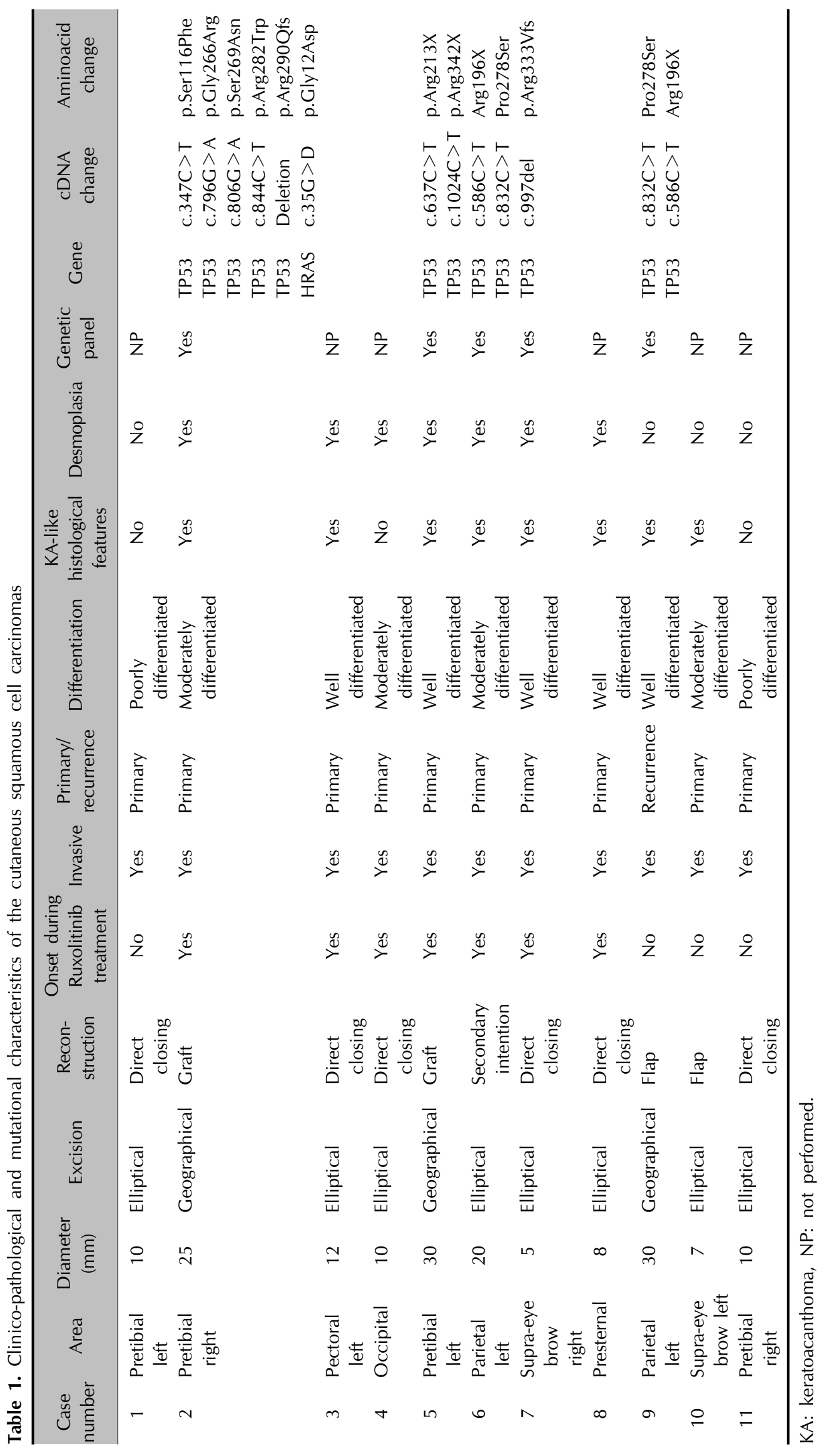



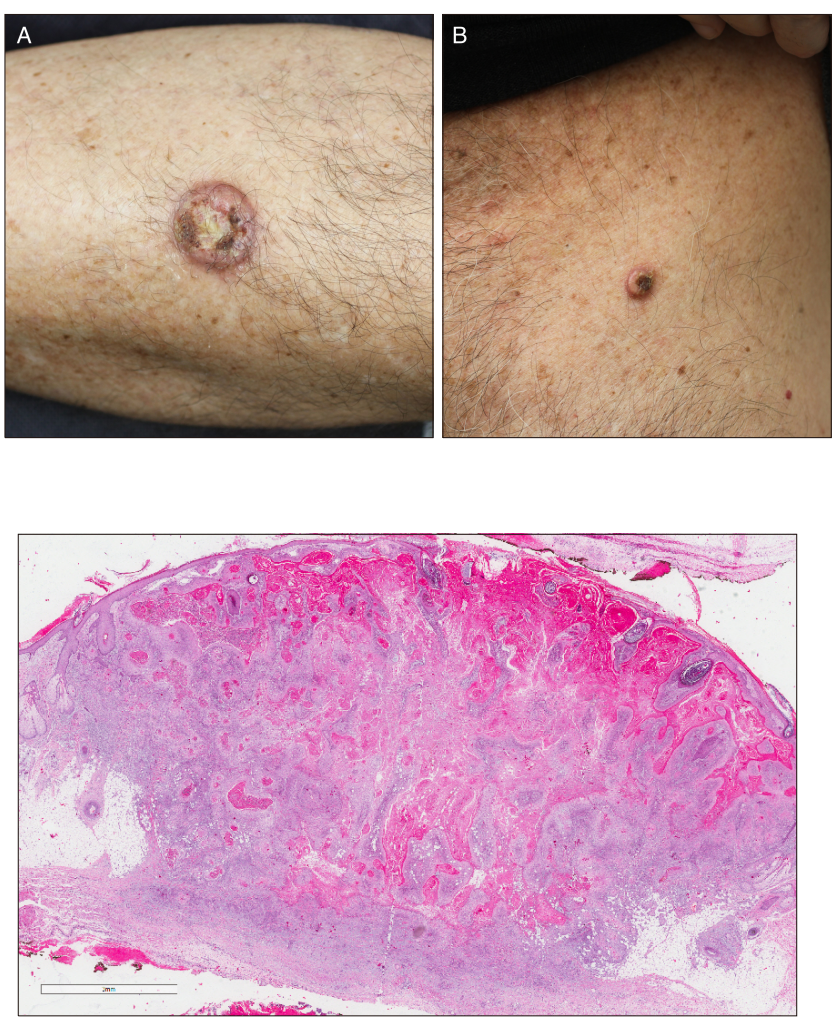

Fig. 2. Proliferating keratin-filled invagination of the epidermis with areas of deep penetrating strands $(\mathrm{H} \& \mathrm{E}, \times 10)$.

one recurrence in sun-exposed areas that corresponded to cSCCs over an 18-month period of time (Table 1). All the tumors were rapidly growing crateriform lesions that clinically suggested keratoacanthomas (KA) (Fig. 1). Histologically, all these tumors consisted of CSCCs and six out of seven lesions also showed KA-like features (Table 1, Fig. 2). Areas of fibrosis at the tumor invasion fronts were observed in all the lesions (Fig. 3). All the tumors were treated with surgical excision (Table 1 ) with no recurrence except for lesion number 6 , located on the left parietal area, which showed recurrence 2 months after removal. This lesion (case 9) was excised and irradiated with no further relapses. No decrease in the count number of leukocytes or lymphocytes per $\mathrm{mm}^{3}$ was observed during treatment with ruxolitinib. This treatment was discontinued in December 2015. Four months after ruxolitinib being withdrawn, the patient still developed a new KA-like cSCC (case 10). In a further 12 month follow-up, the patient has only developed a poorly differentiated $\operatorname{cSCC}$ with no KA-like features on the leg (case 11).

Mutational analysis was performed on the 6 lesions in which good quality DNA could be obtained by next-generation sequencing with a small targeted panel covering the exonic regions of TP53, KRAS, NRAS, HRAS, BRAF,

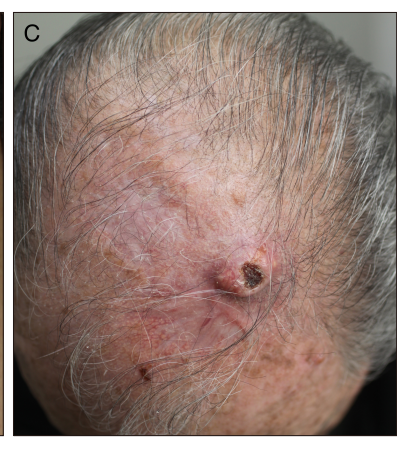

Fig. 1. Rapidly growing crateriform tumors on the pretibial area (A), presternal (B) and parietal (C).

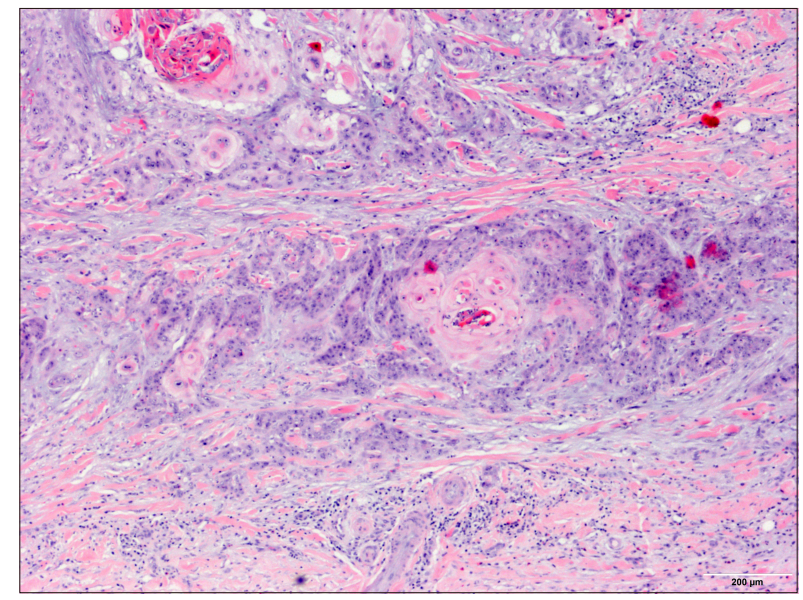

Fig. 3. Small nests of keratinizing cells surrounded by a fibromyxoid and keloid-like stroma at the deep invasion front $(\mathrm{H} \& \mathrm{E}, \times 40)$.

PIK3CA, EGFR and KIT genes (GeneRead; Qiagen, Hilden, Germany) and sequenced on a Miseq (illumina, San Diego, CA, USA). The mutational analysis could not be performed in 6 additional lesions due to inadequate DNA quality. Frequent mutations in TP53, previously reported in CSCC, were found in 5 cases and a HRAS mutation in one case (Table 1). The recurrent cSCC (case 9) showed the same mutational profile (mutations in TP53) than that found in the primary lesion (case 6). None of these mutations were observed in granulocytes from this patient, which were mainly characterized by the presence of the p. JAK2V617F mutation. The study was approved by the local ehtics committee (Hospital del Mar. CEIC 2010/3913/I). We received the patient's consent form about publishing all photographic materials.

\section{DISCUSSION}

We here report a patient who developed rapidly growing cSCCs while being treated with ruxolitinib. Although he had developed several skin cancers before starting ruxolitinib, including a cSCC, the striking clinicopathological 
resemblance between all the rapidly growing $\mathrm{CSCC}$ and their development over a short period of time, suggests the role of this drug as the inducer of the patient's tumors. The JAKs are a family of non-receptor tyrosine kinases which can be recruited to cytokine and growth factor receptors where they translate signals triggered by ligand binding into intracellular responses ${ }^{1}$. The best characterized downstream pathways activated by JAK signaling are the signal transducers and activators of transcription (STATs). STATs are a family of transcription factors that drive the expression of genes involved in proliferation, apoptosis, migration as well as in the production of inflammatory proteins. Inhibition of JAK kinase activity can block the constitutive activation of JAK-STAT pathway that characterizes myeloproliferative neoplasms ${ }^{2}$.

Extrahematologic side effects induced by ruxolitinib are usually mild and include diarrhea, ecchymosis and headache $^{3}$. However, as predicted by its in vitro immune deregulation, JAK2 inhibitors may also trigger urogenital tract infections as well as opportunistic infections ${ }^{4-6}$. Moreover, some skin adverse side effects such as herpes zoster infection, herpes simplex virus reactivation, disseminated molluscum contagiosum and drug eruption have been reported $^{7-9}$.

The association of ruxolitinib and skin cancer has also been previously documented in the literature. A higher rate of basal cell and cSCCs was reported in the ruxolitinib arm of the randomized study of efficacy and safety in PV with JAK Inhibitor INCB018424 versus best supportive care (RESPONSE) study ${ }^{7}$. However, the number of patients with a history of nonmelanoma skin cancer or precancerous skin lesions was also higher in the arm of patients receiving ruxolitinib ${ }^{7}$. A similar case to ours was recently reported by Fabiano et al. ${ }^{10}$. They treated a $72-$ year-old patient with myelofibrosis who developed multiple, eruptive, simultaneous cSCCs with KA-like features two months after starting on ruxolitinib. No additional lesions appeared in the 10-month follow-up period after ruxolitinib had been discontinued. The lesions reported by Fabiano et al. ${ }^{10}$ are clinically and histologically very similar to the ones here described and must be distinguished from KAs. Specially challenging is the histological distinction between KA with malignant transformation and KA-like SCC. They are both exoendophytic lesions showing invaginated infundibulum and pale pink cells with glassy appearance as well as a conventional SCC component. However, in KA-like SCC, the KA and SCC components are mixed and no clear boundaries can be defined. On the contrary, a clear-cut border between the KA and the SCC components can be distinguished in KA with malignant transformation $^{11}$.
The etiology of cSCC is multifactorial. Ultraviolet radiation is the most relevant etiological factor, inducing numerous $\mathrm{C}$ to $\mathrm{T}$ mutations (UV signature) in genes such as TP53, HRAS and NOTCH1. However, many other factors, such as genetic susceptibility, inflammation and alterations in local and systemic immunity may also play a role for the development of cSCC. In addition, several drugs may also favor the development of cSCC through different mechanisms. In this regard, the development of rapidly growing cSCCs observed in our patient is similar to those observed in patients taking sorafenib and vemurafenib, both having in common the inhibition of RAF isoforms ${ }^{12,13}$. It has been proposed that RAF inhibitor-driven activation of the mitogen-activated protein kinase pathway might unmask oncogenic events in keratinocytes harboring preexisting sun-induced RAS mutations. Of note, RAS mutations are found in $20 \% \sim 60 \%$ of vemurafenib-induced skin tumors $^{13}$. In contrast, we found HRAS mutations in only $7 \%$ of the patient's tumors, a figure that is similar to that reported in common $\mathrm{cSCC}^{14}$. An alternative explanation would be the impairment of immunosurveillance as a result of JAK inhibition by ruxolitinib. JAK inhibition results in the reduction of pro-inflammatory cytokines such as IL-6 and IL-23 as well as in downregulation of the Th17 cell differentiation programme ${ }^{15,16}$. These changes lead to a decrease in natural killer, dendritic and CD4 + T cell populations. Interestingly, a similar immunological microenvironment, favouring cSCC development, is observed in organ transplant patients, who show a Th17 cell differentiation and CD4 + cell decrease due to exposure to immunosuppressants ${ }^{17,18}$.

In our patient, the previous ingestion of hydroxyurea, although brief, may have played a synergistic effect in the induction of cSCC. Hydroxyurea is an antimetabolite used in the treatment of myeloproliferative disorders and may predispose to the development of actinic keratosis, Bowen's disease and $\mathrm{CSCC}^{19}$.

In conclusion, we report a patient with PV who developed multiple cSCC while on ruxolitinib suggesting that JAK1/2 inhibition may trigger the development of cSCCs through immunologic mechanisms. We recommend frequent and thorough dermatological examinations in patients who take this drug and specially in those who have a history of photodamage, skin cancer and/or previous hydroxyurea intake.

\section{CONFLICTS OF INTEREST}

The authors have nothing to disclose. 


\section{ORCID}

Álvaro March-Rodriguez, https://orcid.org/0000-0002-4637-7079

Beatriz Bellosillo, https://orcid.org/0000-0002-5335-2726

Alberto Álvarez-Larrán, https://orcid.org/0000-0001-6387-4619

Carles Besses, https://orcid.org/0000-0003-1806-3440

Ramon M Pujol, https://orcid.org/0000-0002-5622-6055

Agustí Toll, https://orcid.org/0000-0003-2656-0076

\section{REFERENCES}

1. Rane SG, Reddy EP. JAKs, STATs and Src kinases in hematopoiesis. Oncogene 2002;21:3334-3358.

2. Jatiani SS, Baker SJ, Silverman LR, Reddy EP. Jak/STAT pathways in cytokine signaling and myeloproliferative disorders: approaches for targeted therapies. Genes Cancer 2010;1:979-993.

3. Deisseroth A, Kaminskas E, Grillo J, Chen W, Saber H, Lu HL, et al. U.S. Food and Drug Administration approval: ruxolitinib for the treatment of patients with intermediate and high-risk myelofibrosis. Clin Cancer Res 2012;18:32123217.

4. Caocci G, Murgia F, Podda L, Solinas A, Atzeni S, La Nasa G. Reactivation of hepatitis $B$ virus infection following ruxolitinib treatment in a patient with myelofibrosis. Leukemia 2014; 28:225-227.

5. Goldberg RA, Reichel E, Oshry LJ. Bilateral toxoplasmosis retinitis associated with ruxolitinib. N Engl J Med 2013;369: 681-683.

6. Verstovsek S, Mesa RA, Gotlib J, Levy RS, Gupta V, DiPersio JF, et al. A double-blind, placebo-controlled trial of ruxolitinib for myelofibrosis. N Engl J Med 2012;366:799807.

7. Vannucchi AM, Kiladjian JJ, Griesshammer M, Masszi T, Durrant S, Passamonti $F$, et al. Ruxolitinib versus standard therapy for the treatment of polycythemia vera. N Engl J Med 2015;372:426-435.

8. Verstovsek S, Mesa RA, Gotlib J, Levy RS, Gupta V, DiPersio JF, et al. Efficacy, safety, and survival with ruxolitinib in patients with myelofibrosis: results of a median 3-year follow-up of COMFORT-I. Haematologica 2015;100:479-488.
9. Shreberk-Hassidim R, Ramot Y, Zlotogorski A. Janus kinase inhibitors in dermatology: a systematic review. J Am Acad Dermatol 2017;76:745-753.e19.

10. Fabiano A, Calzavara-Pinton P, Monari P, Moggio E, Pellacani G, Manganoni AM, et al. Eruptive squamous cell carcinomas with keratoacanthoma-like features in a patient treated with ruxolitinib. Br J Dermatol 2015;173:1098-1099.

11. Ogita A, Ansai SI, Misago N, Anan T, Fukumoto T, Saeki H. Histopathological diagnosis of epithelial crateriform tumors: keratoacanthoma and other epithelial crateriform tumors. J Dermatol 2016;43:1321-1331.

12. Smith KJ, Haley $\mathrm{H}$, Hamza S, Skelton HG. Eruptive keratoacanthoma-type squamous cell carcinomas in patients taking sorafenib for the treatment of solid tumors. Dermatol Surg 2009;35:1766-1770.

13. Oberholzer PA, Kee D, Dziunycz P, Sucker A, Kamsukom $N$, Jones $R$, et al. RAS mutations are associated with the development of cutaneous squamous cell tumors in patients treated with RAF inhibitors. J Clin Oncol 2012;30:316-321.

14. Forbes SA, Beare D, Gunasekaran P, Leung K, Bindal N, Boutselakis $\mathrm{H}$, et al. COSMIC: exploring the world's knowledge of somatic mutations in human cancer. Nucleic Acids Res 2015;43:D805-D811.

15. Parampalli Yajnanarayana S, Stübig T, Cornez I, Alchalby H, Schönberg K, Rudolph J, et al. JAK1/2 inhibition impairs $\mathrm{T}$ cell function in vitro and in patients with myeloproliferative neoplasms. Br J Haematol 2015;169:824-833.

16. Spoerl S, Mathew NR, Bscheider M, Schmitt-Graeff A, Chen $\mathrm{S}$, Mueller T, et al. Activity of therapeutic JAK 1/2 blockade in graft-versus-host disease. Blood 2014;123:3832-3842.

17. Kosmidis M, Dziunycz $P$, Suárez-Fariñas M, Mühleisen B, Schärer $\mathrm{L}$, Läuchli $\mathrm{S}$, et al. Immunosuppression affects CD4 + mRNA expression and induces Th2 dominance in the microenvironment of cutaneous squamous cell carcinoma in organ transplant recipients. J Immunother 2010;33:538-546.

18. Harwood CA, Toland AE, Proby CM, Euvrard S, Hofbauer GFL, Tommasino $M$, et al. The pathogenesis of cutaneous squamous cell carcinoma in organ transplant recipients. Br J Dermatol 2017;177:1217-1224.

19. Sanchez-Palacios C, Guitart J. Hydroxyurea-associated squamous dysplasia. J Am Acad Dermatol 2004;51:293-300. 